\title{
Improve the Marshall stability of porous asphalt pavement with HDPE addition
}

\author{
Elsa Eka Putri ${ }^{1, *}$ and Oliensia Vasilsa $^{1}$ \\ ${ }^{1}$ Department of Civil Engineering, Universitas Andalas, Padang, Indonesia
}

\begin{abstract}
Porous asphalt is a gap graded pavement that is $20 \%$ air voids which enables rainwater that falls on the road surface to flow through the pavement and into drainage on the side of the road. Porous asphalt has a high shear resistance and dries quickly but its stability is low, it is costly to maintain and needs replacing after only a short time. Despite these disadvantages, porous asphalt is still a good choice in area that experiences heavy annual rainfall. High Density Polyethylene (HDPE), an opaque plastic, is harder and stronger than porous asphalt with a tensile strength of 3100-5500 psi. It is resistant to high temperatures. This study aims to investigate the effect of various percentages of HDPE as an additive to produce an HDPE Asphalt Binder for porous asphalt pavement. Marshall parameters were determined based on the AAPA 2004 standard. It was found that 4\% HDPE achieved a maximum stability value of $870 \mathrm{~kg}$ at the optimum asphalt content for porous asphalt pavement was $5.54 \%$. Stability of porous asphalt pavement with optimum asphalt content value was $61.1 \%$ higher after the addition of HDPE. Thus, the use of HDPE as an additive in Asphalt Binder was able to increase the binding strength of the asphalt minimising the disadvantages of the low stability of traditional porous asphalt pavement.
\end{abstract}

\section{Introduction}

The type of asphalt mixture is generally determined by the aggregate gradation, asphalt, and the mixing or compacting temperature. Typical porous asphalt had an open-graded surface and was initially developed in countries as a wearing surface spread over the surface of a more stable base [1].

Porous asphalt is a pavement surface that allows water allows to enter through the foundation structure of the pavement and flow to the edge to the soil [2]. Porous asphalt mixture generally has a low stability value which is highly dependent on the quality of binder, since the strength of the porous asphalt depends on the properties of the binder to hold the aggregate together.

An asphalt binder can be modified with the addition of material to improve the physical properties of asphalt such as viscosity, penetration, and a softening point (Directorate General of Highways, 2004) [3]. Some additives which improve the quality of asphalt

*Corresponding author: elsaeka@eng.unand.ac.id; elsaeka@gmail.com 
include elastomeric polymers like rubber or plastics from waste material which, like asphalt, melt on heating [4].

Plastic, like asphalt, has hydrophobic and thermoplastic properties and this makes it a compatible and potent additive. The use of plastic waste as an asphalt additive will also indirectly reduce the amount of waste disposal. Plastics are synthetic polymers made from petroleum which is a non-renewable resource that cannot quickly be degraded by microorganisms in the environment. This means reusing plastic waste as an additive in asphalt mixture has environmental benefits while producing a more durable product for road surfacing.

\section{Literature review}

\subsection{Porous asphalt}

Porous asphalt is an asphalt mixture with a higher porosity than the other pavement surfacing materials. Its porosity is a result of decreasing the proportion of fine aggregates in the mix. This results in larger pores and void content, producing a rougher surface with good skid resistance [4].

Porous asphalt is $85 \%$ coarse aggregate by weight, and the pores between the coarse aggregate particles result in an open and hollow structure which increases the ability of the surface to enable water to drain either vertically or horizontally. The Australian Asphalt Pavement Association (AAPA) specifications for porous asphalt aggregate are shown in Table 1.

Table 1. Porous asphalt specification based on AAPA standard.

\begin{tabular}{|c|c|c|}
\hline Criteria & $\mathbf{2 0 0 4}$ & $\mathbf{1 9 9 7}$ \\
\hline Cantabro loss (\%) & Max 35 & Maks 20 \\
\hline Run Flow test (\%) & Max 0.3 & Maks 0.3 \\
\hline Void in Mineral Aggregate (\%) & $18-25$ & $10-25$ \\
\hline Marshall Stability (kg) & Min 500 & Min 500 \\
\hline Marshall Flow (mm) & $2-6$ & $2-6$ \\
\hline Marshall Quotient (kg/mm) & Maks 400 & Maks 400 \\
\hline Number of Blows & 50 & - \\
\hline
\end{tabular}

Porous asphalt is a gap graded pavement which is mainly reliant on binder quality to bind the aggregate to produce the high stability and durability. The porosities in the asphalt results in a dual drainage system, water can flow on top of the surface out to the side of the road or seep into the layer and then flow to the edge of the road. For this dual water drainage process to be effective an impermeable base layer is necessary so that water does not seep into the road foundation layer ruining the structure of the pavement [4].

\subsection{High Density Polyethylene (HDPE)}

HDPE or high-density polyethylene is one type of plastic that is commonly used for bottles of liquid soap, lotion, shampoo, and floor cleaning fluid. HDPE is durable, hard, opaque, 
and resistant to high temperatures. It is a thermoplastic (meltable) plastic made from petroleum with a melting point in the range $200-280^{\circ} \mathrm{C}$ [5].

The tensile strength, the ability to withstand a tensile (pulling) force, of HDPE is moderately high at 21,000-38,000 $\mathrm{kPa}$. HDPE has a higher strength than the strength of a $2.5 \mathrm{~cm}^{2}$ cross-section metal rod which is only able to withstand a tensile force of $7000 \mathrm{kPa}$ and breaks if the force is applied more [6].

Kofteci investigated the effect of HDPE sourced from the waste in Hot Mix Asphalt (HMA) pavement. Various proportions were added to the asphalt $(1 \%, 2 \%, 3 \%$, and $4 \%$ ) and the resulting HMA subjected to a Marshall test and Indirect Tensile Test (ITT) [7]. The results showed that $4 \%$ of HDPE had the highest Marshall Stability.

Naskar et al., conducted studies on waste plastic to produce modified asphalt binders using $0-7 \%$ by weight plastic and found that $5 \%$ plastic content yielded optimal performance [8].

Plastic pavement technology has already been trailed in Indonesia. Plastic road construction has been successfully completed in West Java, using 3.5 metric tons of plastic waste material mixed with asphalt to create a $1.8 \mathrm{~km}$ road, covering an area of $9781 \mathrm{~m}^{2}$ and was proved to be more durable and stronger than pavement made without plastic waste [9].

However, in areas with high rainfall like the tropics, a porous road surface material is advantageous yet as far as the author is aware there has been no published work on the use of waste plastics in this type of pavement. Using HDPE as an asphalt mixture additive could well improve its stability which could be especially useful in porous asphalt where the strength of the material relies heavily on the binder to stick the aggregate together. It could be expected that HDPE would increase the durability and stability of porous asphalt pavement so improving its resistance to water damage and weathering. This process would also take used HDPE out of the waste stream by giving it economic value.

In this study, HDPE waste was mixed with asphalt to form a binder for porous asphalt mixture to determine its suitability as an asphalt additive material to enhance the pavement performance. The purpose of this study was to evaluate the amount of asphalt and HDPE to add to the binder to optimize porous asphalt pavement stability and strength and to measure the properties of the resulting material.

\section{Materials and methods}

Samples used for Marshall testing in this study were prepared according to the General Specification 2010 Division 6 Revision 3 of Indonesian Standard [3] using aggregate $<14$ $\mathrm{mm}$ Standard percentage aggregate passes and size distribution of the aggregate used was following aggregate standard up to $14 \mathrm{~mm}$, as shown in Fig. 1.

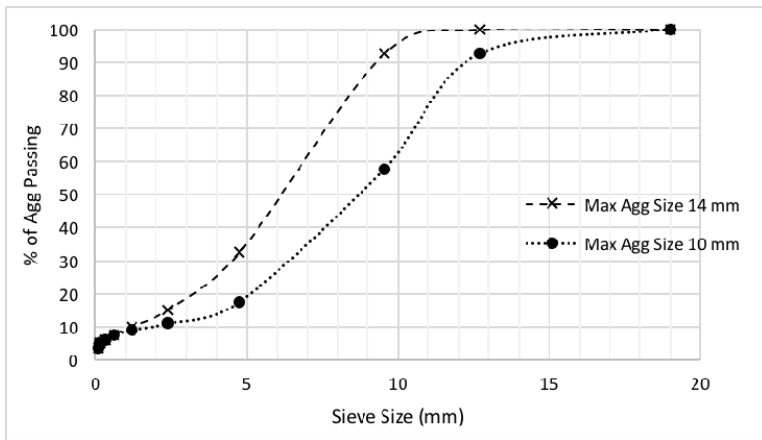

Fig. 1. Aggregate specification of porous asphalt pavement. 
The asphalt was 60/70 penetration and aggregate was prepared following Asphalt Porous specifications as shown in Table 1. The optimum asphalt content for the Porous Asphalt mixture was determined first with content ranges from $4.5-6.5 \%$ by weight of asphalt being trialed.

To determine HDPE, $0 \%, 2 \%, 4 \%, 6 \%, 8 \%$ of HDPE by weight was added to the optimum asphalt content mixture that was determined previously to produce an HDPE plastic asphalt binder. About $1200 \mathrm{~g}$ of this mixture was prepared for each sample to produce a test sample $63.5 \pm 1.27 \mathrm{~mm}$ thick. Cylindrical samples of $50 \mathrm{~mm}$ diameter and $100 \mathrm{~mm}$ height were used for the Marshall hammer test which used 75 blows on each face following the SNI 06 - 2484 - 1991 and AASHTO. T 245 - 97 [10-11] to evaluate the ability of asphalt modified with HDPE to withstand loads without permanent deformation.

Flow, Voids in the Mixture, Voids in the Mineral Aggregate, and Voids filled by asphalt were also measured to determine the optimum proportion of HDPE. Results of the Marshall Tests are presented in Fig. 2-6. The TFOT (Thin Film Oven Test) was performed to identify the aging process in certain short time that might be occurred during storage, moving to the plant and mixing it, then transportation, spreading, and compaction.

\section{Results and discussion}

\subsection{Aggregate and asphalt}

The rheological changes due to the addition of HDPE to asphalt is presented in Table 2, that shows the properties of asphalt with various HDPE addition.

Table 2. The properties of Asphalt Pen 60-70 with HDPE addition

\begin{tabular}{|c|c|c|c|c|c|c|c|c|}
\hline \multirow{2}{*}{ Properties } & \multicolumn{5}{|c|}{ HDPE Addition } & \multirow{2}{*}{ Unit } & \multirow{2}{*}{ Standard } & \multirow{2}{*}{$\begin{array}{l}\text { Value of } \\
\text { Standard }\end{array}$} \\
\hline & $0 \%$ & $2 \%$ & $4 \%$ & $6 \%$ & $8 \%$ & & & \\
\hline Ductility & 100 & 100 & 100 & 73 & 70 & $\mathrm{~cm}$ & $\begin{array}{c}\text { SNI 06- } \\
2432- \\
1991\end{array}$ & $\geq 100$ \\
\hline Ductility (T-FOT) & 68.5 & 100 & 100 & 85 & 80 & $\mathrm{~cm}$ & $\begin{array}{c}\text { ASTM D } \\
1754\end{array}$ & $\geq 50$ \\
\hline Penetration & 66.5 & 59.5 & 52.9 & 43.1 & 40.8 & - & $\begin{array}{c}\text { SNI 06- } \\
2456- \\
1991\end{array}$ & $60-70$ \\
\hline $\begin{array}{c}\text { Penetration (T- } \\
\text { FOT) }\end{array}$ & 54.2 & 75.2 & 69.9 & 65.1 & 58.4 & - & $\begin{array}{c}\text { ASTM D } \\
1754\end{array}$ & $\geq 54$ \\
\hline Specific Gravity & 1.0452 & 1.0377 & 1.0335 & 1.0330 & 1.0413 & - & $\begin{array}{c}\text { SNI 06- } \\
2441- \\
1991\end{array}$ & $\geq 1.00$ \\
\hline Flash Point & 273 & 270 & 288 & 290 & 286 & ${ }^{\circ} \mathrm{C}$ & $\begin{array}{c}\text { SNI 06- } \\
2433- \\
1991\end{array}$ & $\geq 232$ \\
\hline Burning Point & 354 & 317 & 301 & 310 & 315 & ${ }^{\circ} \mathrm{C}$ & $\begin{array}{c}\text { SNI 06- } \\
2433- \\
1991\end{array}$ & $\geq 232$ \\
\hline Softening Point & 55.5 & 72 & 84.5 & 97 & 95.5 & ${ }^{\circ} \mathrm{C}$ & $\begin{array}{c}\text { SNI 06- } \\
2434- \\
1991\end{array}$ & $\geq 48$ \\
\hline $\begin{array}{c}\text { Average Loss } \\
\text { Weight }\end{array}$ & 0.031 & 0.010 & 0.070 & 0.081 & 0.15 & $\%$ & $\begin{array}{c}\text { SNI 06- } \\
2440- \\
1991\end{array}$ & $\leq 0.8$ \\
\hline
\end{tabular}

$* \mathrm{~T}-\mathrm{FOT}=$ the asphalt was aged in the TFOT device for 5 hours at $163^{\circ} \mathrm{C}$. 
As can be seen from Table 2, most samples met the specifications. The addition of HDPE did not change the rheology behavior of the asphalt. The ductility, penetration, and softening point remained unaffected.

Ductility shows the adherence of aggregate and asphalt that holds the aggregate in place. Penetration after the aging process was similar in range to that without an aging process in Table 2 . The ductility without aging for a plastic content of $6 \%$ and $8 \%$ was still within specifications at the value of $80-85 \mathrm{~cm}$ even though a high percentage of plastics were being added.

\subsection{Optimum asphalt content determination}

The results of this determination are shown in Table 3. It was concluded that optimum asphalt content for porous asphalt was $5.54 \%$ based on the mean values of the Marshall parameters that fulfill the criteria for porous asphalt. This was the asphalt content used in subsequent experiments with the addition of HDPE.

Table 3. Marshall test results of porous asphalt without HDPE.

\begin{tabular}{|c|c|c|c|c|c|}
\hline \multirow{2}{*}{ Criteria } & \multicolumn{5}{|c|}{ Asphalt Content without HDPE } \\
\cline { 2 - 6 } & $\mathbf{4 . 5 \%}$ & $\mathbf{5 . 0 \%}$ & $\mathbf{5 . 5 \%}$ & $\mathbf{6 . 0 \%}$ & $\mathbf{6 . 5 \%}$ \\
\hline Stability (kg) & 617.06 & 427.06 & 563.84 & 495.60 & 579.74 \\
\hline Flow (mm) & 3.04 & 3.21 & 4.45 & 3.85 & 4.27 \\
\hline Void in Mineral Aggregate (\%) & 23.03 & 24.10 & 22.49 & 23.96 & 25.91 \\
\hline Void in Mixture (\%) & 16.37 & 16.50 & 13.65 & 14.23 & 15.38 \\
\hline Void Filled with Asphalt & 28.97 & 31.57 & 39.43 & 40.94 & 40.86 \\
\hline Marshall Quotient & 204.22 & 132.87 & 130.15 & 135.92 & 137.54 \\
\hline
\end{tabular}

\subsection{Marshall properties}

\subsubsection{Stability}

The value of Marshall Stability is intended to see the changing in Stability value of the mixture for various value of plastics (HDPE) content in asphalt.

Fig. 2 shows stability as a function of HDPE content. The stability increases up to $4 \%$, HDPE and then decreases when the percentage exceeds this. This value for maximum stability may be due to the fact that at $4 \%$ plastic the binder penetration is low, but the ductility is still more than $100 \mathrm{~cm}$. As more plastic was added the penetration of the binder continued to decrease along with the ductility (as shown in Table 2) leading to lower stability. The stability values of all the samples meet the AAPA 2004 standard (> $500 \mathrm{~kg}$ ).

\subsubsection{Flow}

Marshall Flow measured simultaneously with Marshall Stability, measured the vertical deformation of the samples while loaded. The flow value for the porous asphalt with HDPE plastics addition is presented in Fig. 3.

The flow value for $0 \%$ plastic content was $5.04 \mathrm{~mm}$. An increase in plastic content resulted in an increase in flow up to an optimum value of $2 \%$ plastic content $(6.51 \mathrm{~mm})$. Further addition of plastic caused the flow to decrease possibly because the penetration of 


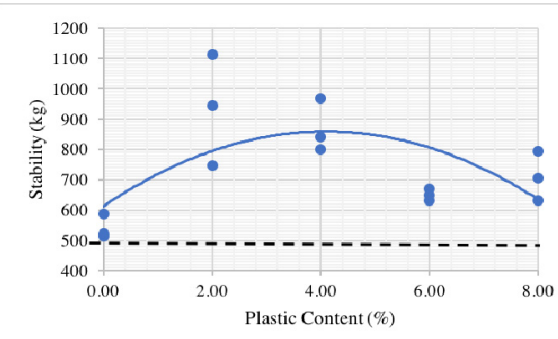

Fig. 2. Stability (kg) vs. plastic content (\%).

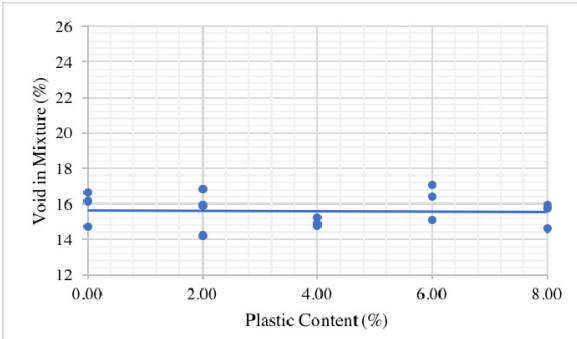

Fig. 4. VIM (\%) vs. plastic content (\%).

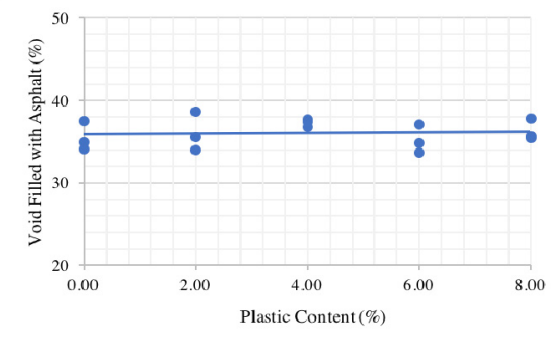

Fig. 6. VFA (\%) vs. plastic content (\%).

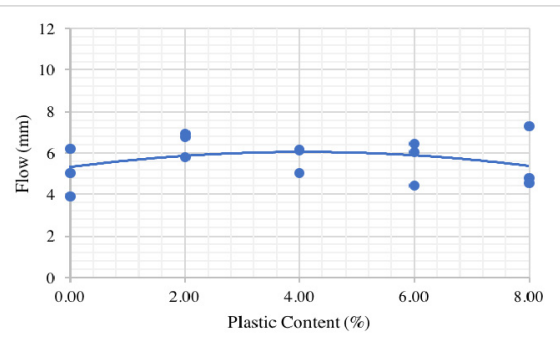

Fig. 3. Flow (mm) vs. plastic content (\%).

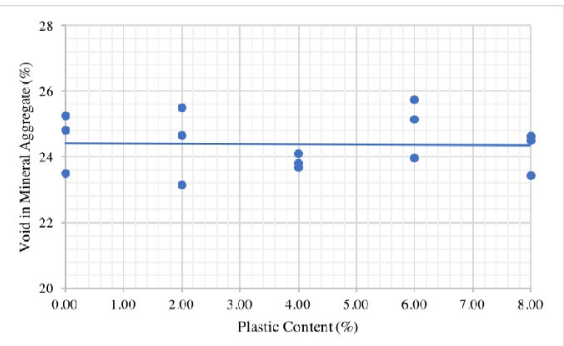

Fig. 5. VMA (\%) vs. plastic content (\%).

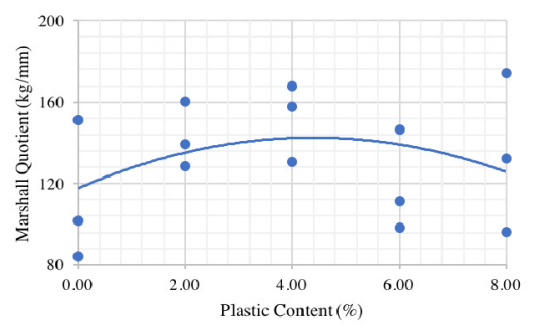

Fig. 7. MQ (kg/mm) vs. plastic content (\%)

the binder decreases as the HDPE increases. Mean values of each mixture trialed met the standards specified by AAPA 2004.

\subsubsection{Void in Mixture (VIM)}

VIM shows the percentage of voids in the mix. VIM affects the durability of the aggregateasphalt mixture, the higher the value, the greater the number of voids in the mixture.

As shown in Fig. 4, the highest average VIM value was at $6 \%$ plastic content $(16 \%$ voids) and the lowest average VIM value at $4 \%$ plastic content ( $15 \%$ voids). There was little variation in VIM with plastic content. This is expected as VIM is related to the primary material used and will remain the same with the addition of plastic content because the total amount of binder in the aggregate remains the same.

\subsubsection{Void in Mineral Aggregate (VMA)}

Similarly, it was not expected that VMA would be influenced or changed by asphalt binder content. As shown in Fig. 5 this was, in fact, the case. The average value of the VMA was 
$25 \%$ at $6 \%$ plastic content, and the lowest VMA value was similar at $24 \%$ at $4 \%$ plastic content.

\subsubsection{Void Filled with Asphalt (VFA)}

The average value of VFA of $36.76 \%$ is found at $4 \%$ plastic content and the lowest VFA value of $34.69 \%$ at $6 \%$ plastic content, as shown in Fig. 6 . This lack of variation is also expected as VFA tends to remain the same when the plastic content is varied because it has the same total weight of the mixture.

\subsubsection{Marshall Quotient (MQ)}

The MQ is calculated from the results of the stability and flow tests as the ratio of load (stability) to deformation (flow) and is an indication of the mixture's stiffness. The higher the ratio, the stiffer the mixture is.

Fig. 7 shows a graph of the relationship between the plastic content and the MQ. The highest average value of the MQ was with $4 \%$ plastic content $(152.06 \mathrm{~kg} / \mathrm{mm})$ while the lowest MQ was with $0 \%(112.31 \mathrm{~kg} / \mathrm{mm})$.

These results indicate 4\% HDPE provided the highest Marshall Quotient with the lowest flow and the highest stability. However, if MQ is too high cracking occurs more easily due to the higher the stiffness of the mixture. Nevertheless, all the MQ values of the samples in this study meet the standards of AAPA, 2004 of under $400 \mathrm{~kg} / \mathrm{mm}$.

The optimal percentage of plastic content for stability, low value, MQ, and voids in the mixture, in $5.54 \%$ asphalt was $4 \%$. With this addition of HDPE stability was improved by $61.1 \%$.

Table 4. Marshall test results of porous asphalt with HDPE plastic.

\begin{tabular}{|c|c|c|c|c|c|}
\hline \multirow{2}{*}{ Criteria } & \multicolumn{5}{|c|}{ HDPE plastic content } \\
\cline { 2 - 6 } & $\mathbf{0 \%}$ & $\mathbf{2 \%}$ & $\mathbf{4 \%}$ & $\mathbf{6 \%}$ & $\mathbf{8 \%}$ \\
\hline Stability (kg) & 540 & 800 & 870 & 788 & 600 \\
\hline Flow (mm) & 5.04 & 6.51 & 5.76 & 5.62 & 5.55 \\
\hline Void in Mineral Aggregate (\%) & 24.51 & 24.43 & 23.85 & 24.95 & 24.19 \\
\hline Void in Mixture (\%) & 15.82 & 15.65 & 14.96 & 16.17 & 15.42 \\
\hline Void Filled with Asphalt & 35.51 & 36.03 & 37.29 & 35.21 & 36.28 \\
\hline Marshall Quotient & 112.31 & 142.77 & 152.06 & 118.77 & 134.24 \\
\hline
\end{tabular}

\section{Conclusions}

Based on the findings of this study, the following conclusions are drawn. Adding 4\% HDPE plastic to asphalt increased ductility of the binder, especially the ductility after thin film oven test (T-FOT). $2 \%$ and $4 \%$ HDPE binder provide the best penetration values, the penetration is lower but the ductility was high. The flash point and softening point increased with the increasing HDPE content indicating that addition of HDPE to the binder makes it less susceptible to temperature changes. Meanwhile, the Burning Point was not affected by the HDPE content in the asphalt. The optimum asphalt content for Porous 
Asphalt was achieved at $5.54 \%$. The stability values of the porous asphalt were found to increase with the amount of HDPE up to 4\% HDPE plastic in the asphalt (optimum limit). After that, the stability values decreased. Mixes with higher HDPE content (6\% and 8\%) were less stable and had a higher flow, but VIM, VMA, and VFA are not affected by HDPE content. The MQ value of the sample in this study easily meets the 2004 AAPA standard under $400 \mathrm{~kg} / \mathrm{mm}$. The optimum plastics content for Porous Asphalt Pavement achieved in this investigation was $4 \%$ at $5.54 \%$ asphalt content and with this addition, the stability was improved by $61.1 \%$. These results suggest strongly that HDPE could be of economic value as a useful addition to porous asphalt pavement thus diverting it from the waste stream and resulting in roads that are more able to withstand tropical weather.

The author would like to acknowledge the Program Bantuan Seminar Luar Negeri, Faculty of Engineering, Andalas University, Padang, West Sumatera, Indonesia for funding of this research.

\section{References}

1. Australian Asphalt Pavement Association, National Asphalt Specification (Australian Asphalt Pavement Association, Australia, 2004)

2. B.K. Ferguson, Porous pavement: integrative studies in water management and land management (CRC Press, Florida, 2005)

3. Directorate of Highways Indonesia, General Specifications, Revision 3, (Directorate of Highways Indonesia, Jakarta, 2010)

4. J.G. Cabrera, M.O. Hamzah, Proc. of Performance and Durability of Bituminous Materials Symposium (1994)

5. H. Domininghaus, Plastics for engineers: materials, properties, application (Oxford University Press, Oxford, 1993)

6. L. Inggaweni, Suyatno, Prosiding Seminar Nasional Kimia (2015)

7. S. Kofteci, Procedia Engineering 161, (2016)

8. M. Naskar, T.K. Chaki, K.S. Reddy, Thermochimica Acta 509, 1-2 (2010)

9. F. Hidayat, Dow perkuatan pegelolaan limbah plastik di Indonesia. Available at: http://www.beritasatu.com/ekonomi/472572-dow-perkuat-pengelolaan-limbah-plastikdi-indonesia.html (2018)

10. Standar Nasional Indonesia, Asphalt Mixtures, Test Method by Marshall Apparatus SNI 06-2489-1991 (Bandar Standarisasi Nasional, Jakarta, 1991)

11. AASHTO, Standard Method of test for Resistance to Plastic Flow of Bituminous Mixtures Using Marshall Apparatus T 245-97 (American Association of State Highway and Transportation Officials, Washington D.C., 2015) 